Historia: Jurnal Program Studi Pendidikan Sejarah

Vol 4. No 1 (2019):58-68

P-ISSN 2301-8305

E-ISSN 2599-0063

\title{
PENERAPAN MODEL PEMBELAJARAN LISTENING TEAM UNTUK DISIPLIN SISWA PADA MATA PELAJARAN SEJARAH DI SMA NEGERI 2 KERINCI
}

\section{APPLICATION OF LISTENING TEAM LEARNING MODEL TO DISCIPLINE STUDENTS IN HISTORY LESSONS IN KERINCI STATE 2 HIGH SCHOOL}

\author{
Apdelmi \\ Prodi Pendidikan Sejarah, Fakultas Keguruan dan Ilmu Pendidikan, Universitas Jambi \\ Apdelmi1985@gmail.com
}

\begin{abstract}
Abstrak
Kedisiplinan siswa dalam pembelajaran sejarah merupakan hal yang sangat penting diperhatikan, kedisiplinan pada saat proses belajar mengajar di kelas merupakan salah satu indikator keberhasilan didalam pendidikan. Permasalahan Kedisiplinan dalam pembelajaran sejarah adalah Model pembelajaran sejarah yang cenderung konvensional yang masih kurang bisa meningkatkan disiplin siswa dalam belajar, Untuk mengatasi Permasalahan Kedisiplinan pembelajaran sejarah tersebut perlu diterapkan Model PembelajaranListening Teamguna meningkatkan disiplin Belajar pada siswa. Penelitian tindakan kelas ini bertujuan untuk meningkatkan disiplin belajar sejarah siswa kelas XA SMAN 2 Kerinci pada materi "pengaruh Revolusi Prancis, Revolusi Amerika, dan Revolusi Rusia terhadap Perkembangan Pergerakan Nasional Indonesia dengan menggunakan Model Pembelajaran Listening Team.Metode yang digunakan untuk pengambilan data adalah dengan menggunakan metode partisipan dimana peneliti terlibat langsung dalam kegiatan penelitian.Peneliti mengumpulkan data dengan melakukan checklist observasi, kuisioner, dan wawancara. Subjek penelitian adalah siswa kelas X A SMAN 2 Kerinci.Hasil penelitian ini menunjukkan bahwa terjadi peningkatan disetiap siklus.Penelitian ini menggunakan model kemmis dan taggart dengan menggunakan duasiklus.Hasil persentasi rata-rata disiplin belajar siswa mengalami peningkatan secara signifikan. Pada siklus I sebesar $47.87 \%$ dengan kategori sedang dan siklus II Meningkat menjadi $87.15 \%$ dengan kategori sangat baik. Dengan demikian dapat disimpulkan bahwa tindakan pada siklus ke II sudah mencapai kategori yang diharapkan yaitu sebesar 80\%. aktifitas siswa pada siklus 1 berada pada kategori baik dengan persentase $79.99 \%$ kategori baik dan pada siklus II mengalami peningkatan yang signifikan yaitu berada pada kategori sangat baik dengan persentase 91.11\%.Berdasarkan data di atas dapat disimpulkan bahwa penggunaan model Listening Team dapat meningkatkan Disiplin Belajar Sejarah Siswa di kelas X A SMAN 2 Kerinci.
\end{abstract}

\begin{abstract}
Discipline of students in historical learning is a very important thing to note, discipline when teaching and learning in the classroom is one indicator of success in education. Discipline Problems in historical learning are historical learning models that tend to be conventional which are still not able to improve student discipline in learning, To overcome the Problems of Discipline learning history needs to be applied Learning Model Accounts Teams improve the discipline of Learning in students. This classroom action research aims to improve the discipline of learning history of class XA SMAN 2 Kerinci in the material "the influence of the French Revolution, the American Revolution, and the Russian Revolution on the Development of the Indonesian National Movement by using Team Listening Learning Model. The method used for data retrieval is to use participant method where researchers are directly involved in research activities. Researchers collect data by conducting
\end{abstract}


observation checklists, questionnaires, and interviews. The research subjects were students of class $X$ A SMAN 2 Kerinci. The results of this study showed that there was an increase in each cycle. This study used the Kemmis and Taggart models by using two cycle. The results of the average percentage of student learning disciplines increased significantly. In the first cycle of $47.87 \%$ with the medium category and the second cycle increased to $87.15 \%$ with a very good category. Thus it can be concluded that the action in the second cycle has reached the expected category of $80 \%$. student activities in cycle 1 are in the good category with a percentage of $79.99 \%$ in the good category and in the second cycle experienced a significant increase which is in the excellent category with a percentage of $91.11 \%$. Based on the above data it can be concluded that the use of the Listening Team model can improve Historical Learning Discipline Students in class XA SMAN 2 Kerinci.

Kata Kunci: Disiplin belajar, Listening Team.

\section{PENDAHULUAN}

Pendidikan mempunyai arti penting dalam kehidupan, oleh karena itu mutu pendidikan harus senantiasa ditingkatkan. Guru memegang peranan penting dalam suatuproses pembelajaran termasuk dalam perencanaan maupun pelaksanaan kurikulum. (Mulyasa,2006:26). (Ihsan,2008:20)menyatakan bahwa pendidikan merupakan usaha manusia untuk menumbuhkan dan mengembangkan potensi-potensi yang ada di dalam masyarakat dan kebudayaan. (Mulyasa,2013:17) mengemukakanpendidikan merupakan sarana untuk menyiapkan sumber daya manusia generasi masa kini dan sekaligus masa depan. Dapat dipahami pendidikan adalah usaha sadar manusia untuk mengembangkan potensi-potensi yang ada.Melalui pendidikan manusia dapat meningkatkan pengetahuan dan keterampilan serta membentuk sikap yang baik.

Hal ini sesuai dengan pernyataan dalam UU Sisdiknas sebagai berikut: Undang-undang No. 20 Tahun 2003 tentang Sistem Pendidikan Nasional (Sisdiknas) Pasal 1 dinyatakan bahwa pendidikan adalah usaha sadar danterencana untuk mewujudkan suasana belajar dan proses pembelajaranagar peserta didik secara aktif mengembangkan potensi dirinya sehingga memiliki kekuatan spiritual keagamaan, pengendalian diri, kepribadian, kecerdasan, akhlak mulia, serta keterampilan yang diperlukan oleh dirinya, masyarakat, bangsa, dan negara.(Ihsan,2008:20) menyatakan bahwa pendidikan merupakan usaha manusia untuk menumbuhkan dan 
mengembangkan potensi-potensi yang ada di dalam masyarakat dan kebudayaan. (Mulyasa,2013:17) mengemukakanpendidikan merupakan sarana untuk menyiapkan sumber daya manusia generasi masa kini dan sekaligus masa depan. Dapat dipahami pendidikanadalah usaha sadar manusia untuk mengembangkan potensi-potensi yang ada.

Di samping itu Tujuan pembelajaran sejarah adalah untuk membentuk warga Negara yang baik,menyadarkan para siswa mengenal dirinya sebagai orang baik,dan memberikan perspektif sejarah kepada siswa. selain itu Tujuan khusus dari pengajaran sejarah adalah mengajarkan konsep dan memberikan informasi kesejarahan terhadap siswa Proses pembelajaran sejarah sebagai suatu aktivitas untuk meningkatkan pengetahuan, keterampilan, dan sikap siswa berkaitan langsung dengan aktivitas guru dan kinerja guru. Bagaimanapun juga Pengembangan pembelajaran sejarah yang mengembangkan pendidikan intelektual dan pendidikan kemanusiaan/moral, harapannya dapat menopang tercapainya tujuan pendidikan Nasional. Pembelajaran sejarah akan dapat melandasi pendidikan intelektual dan kedisiplinan siswa. Selanjutnya sejarah member pendidikan pengalaman serta pengetahuan sebab disetiap perkara atau peristiwa sejarah tersebut terdapat idea penciptaan, ilmu berbagai disiplin dalam kesejarahannya sendiri, sejarah harus dijadikan sebagai sumber kesadaran ilmu untuk memupuk semangat baru bagi setiap individu untuk memperbaiki segala kelemahannya maupun kesilapan yang telah dilakukan dalam tradisi bermasyrakat memilihkan mental bagi kemajuan individu.Sejarah akan member pemahaman dan pengajaran dalam menghadapi masalah masa sekarang dan yang akan datang.(Gunning,1978:178)

Mengenai Kedisiplinan Siswa dalam pembelajaran sejarah, adalah hal yang sangat penting diperhatikan,adanya peraturan-peraturan yang jelas dan terarah akan sangat mempengaruhi anak pada masa dewasanya nanti, kedisiplinan pada anak harus dilakukan terutama pada saat proses belajar mengajar di kelas.Salah satu indikator keberhasilan Pendidikan adalah kedisiplinan siswa dalam Belajar.Disiplin siswa dalam belajar dipengaruhi oleh faktor eksternal dan faktor internal. Faktor internal 
misalnya kematangan, pertumbuhan, kecerdasan, latihan, motivasi siswa dan kondisi kesehatan siswa. Faktor eksternal meliputi: bahan ajar, alat bantu belajar, suasana belajar.Salah satu faktor eksternal yaitu metode pembelajaran, guru sebagai fasilitator dalam pembelajaran harus mampu membuat siswa disiplin dalam belajar dengan menerapkan berbagai metode pembelajaran aktif (Suprijono, 2009:46).

Adapun yang menjadi permasalahan Kedisiplinan dalam pembelajaran sejarah adalah Model pembelajaran sejarah yang cenderung konvensional Kenyataan masih kurang bisa meningkatkan disiplin siswa dalam belajar, kenyataannya masih ditemukan tindakan yang tidak atau kurang disiplin para siswanya terutama dari keseriusan mengikuti proses pembelajaran di kelas seperti masalah siswa tidak fokus memperhatikan pembelajaran, siswa rebut dikelas, siswa kurang mengerti atau memahami materi pembelajaran yang sudah disampaikan. Untuk mengatasi Permasalahan Kedisiplinan pembelajaran sejarah tersebut perlu diterapkan Model PembelajaranListening Teamguna meningkatkan disiplin Belajar pada siswa yang mana Model PembelajaranListening Team adalah salah satu tipe dalam pelaksanaan model kooperatif.

Melalui Model pembelajaran Listening Team siswa belajar bagaimana menghargai pendapat orang lain, mementingkan kelompok, serta saling menghargai dan menghormati satu sama lain, sehingga belajar bukan menambah pengetahuan saja, akan tetapi belajar juga dapat meningkatkan keseimbangan antara pengetahuan, nilai/sikap dan keterampilan. (Kunandar,2011:370). Listening Team merupakan salah satu teknik pembelajaran aktif.Teknik ini juga termasuk kedalam bentuk pembelajaran Full Class Learning. Pada dasarnya, kegiatan atau teknik ini adalah sebuah cara yang dapat membantu peserta didik agar tetap terfokus dan siap siaga dalam berbagai situasi pembelajaran yang sedang terjadi hingga menimbulkan kedisiplinan belajar sejarah pada siswa.

Oleh karena itu Penentuan model pembelajaran yang tepat oleh guru sangat diperlukan agar sesuai dengan materi pelajaran yang akan diajarkan kepada siswa, Karenannya mengajak anak atau peserta didik menghargai orang yang sedang 
berbicara merupakan hal yang penting dalam dunia pendidikan. Salah satu teknik yang bisa digunakan dalam proses belajar mengajar yang melibatkan siswa disiplin dalam belajar mengunakan Listening Team.

\section{METODOLOGI}

Jenis PTK dalam Penelitian Ini adalah PTK Partisipan Dengan demikian, sejak penencanan panelitian peneliti senantiasa terlibat, selanjutnya peneliti memantau, mencacat, dan mengumpulkan data, lalu menganalisa data serta berakhir dengan melaporkan hasil panelitiannya.Penelitian ini dilakukan di SMAN 2 Kerinci. Subjek penelitian ini adalah Siswa SMAN 2 Kerinci Kelas X A yang berjumlah 40 orang dengan putra 20 dan puteri 20 orang. Teknik pengumpulan data menggunakan anendotal record lembar observasi, lembar pretest dan post test, lembar pedoman wawancara dan lembar checklist skala sikap. Kemudian teknik analisis data menggunakan analisa kualitatif yaitu dan analisa kuantitatif dengan rumus persentase berikut ini:

$\mathrm{P}=\frac{F}{N} \times 100 \%$

dengan rentang persentase Checklist sebagai berikut Kategori sangat baik $81 \%-$ 100\%, Baik 41\%-60\%, Sedang 41\%-60\% Buruk <21\%.

Model PTK menggunakan rancangan Kemmis dan Mc Taggart (Kunandar, 2008:70) penelitan tindakan kelas dilakukan melalui proses yang dinamis dan komplementari yang terdiri dari empat momentum esensial, yaitu Plan, Act, Observe, Reflecting.adapun penjelasan langkah Desain PTK Kemmis dan Taggart, adapun penelitian ini menggunakan II Siklus:

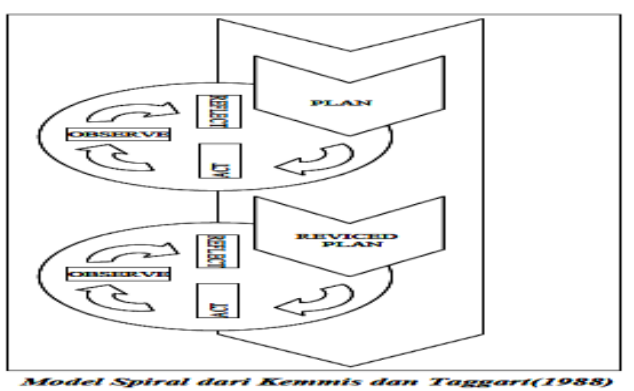


Historia: Jurnal Program Studi Pendidikan Sejarah

Vol 4. No 1 (2019):58-68

P-ISSN 2301-8305

E-ISSN 2599-0063

Gambar 1. Model PTK Spiral Kemmis dan Tagzart(1998)

\section{PEMBAHASAN}

Hasil Penelitian

Penelitian ini terdiri dari II siklus yang mana masing - masing siklus diadakan

3 kali pertemuan. Kondisi awalpembelajaran sejarah dikelas X A SMAN 2 Kerinci tidak begitu maksimal hal ini diketahui berdasarkan wawancara yang dilakukan pada observasi awal yaitu dengan Bapak Herwan Effendi selaku guru sejarah di sekolah tersebut. Beliau menjelaskan bahwa pembelajaran sejarah dapat berlangsung namun pelaksanaannya belum terlalu efektif hal ini terjadi karena tingkat disiplin siswa dalam belajar masih rendah terbukti dengan pengamatan terlihat bahwa masih banyak siswa yang terlambat masuk kekelas meski bel telah di bunyikan, siswa mengobrol dan mengganggu teman saat guru menjelaskan pembelajaran dikelas, masih ada siswa yang tidak mengerjakan tugas, terdapat siswa yang tidak fokus dalam pembelajaran sehingga tidak bisa menjawab pertanyaan yang diajukan oleh guru, tentu saja hal tersebut tidak sesuai dengan cirri-ciri pembelajaran disiplin mental.

Pada Siklus I diadakan 3 kali pertemuan diperoleh hasil yaitu Aktifitas guru pertemuan 1 sebesar $38.33 \%$ kategori buruk, pertemuan 2 sebesar $33.33 \%$ kategori buruk, pertemuan 3 sebesar $40 \%$ kategori buruk, rata-rata persentaseaktifitas guru sebesar $37.22 \%$ dengan kategori buruk. Aktifitas siswa menunjukkan pertemuan 1 sebesar $33.33 \%$ dengan kategori baik, Pertemuan ke 2 sebesar $41.66 \%$ dengan kategori sangat baik, Pertemuan ke 3 sebesar $67.5 \%$ dengankategori baik ,rata-rata aktifitas guru siklus I $67.50 \%$ kategori baik.Pada siklus I ini disiplin belajar sejarah siswa harus di maksimalkan lagi yaitu pada pertemuan 1 dengan 34.16\%, kategori buruk, pertemuan 2 dengan 52.5\% kategori sedang, dan pertemuan 3 dengan 53.05\%.kategori sedang.Rata-rata $47.87 \%$ kategori sedang.

Pada Siklus II aktifitas guru dengan keterangan pertemuan 1 sebesar 90\% kategori baik, pertemuan 2 sebesar 96.6\% kategori baik, pertemuan 3 sebesar $98.3 \%$ kategori sangat baik.rata-rata $94.96 \%$ kategori sangat baik. Aktifitas siswa pertemuan 
Historia: Jurnal Program Studi Pendidikan Sejarah

Vol 4. No 1 (2019):58-68

P-ISSN 2301-8305

E-ISSN 2599-0063

ke I sebesar 85\% kategori sangat baik, pertemuan Ke 2 sebesar 93.33\% kategori sangat baik, pertemuan ke 3 sebesar 95\% kategori sangat baik.rata-rata $91.11 \%$ kategori sangat baik.Pada siklus II ini sikap disiplin belajar siswa mengalami perubahan ke arah yang lebih baik sehingga rata-rata persentase dari ke tiga pertemuan tersebut yaitu $67.51 \%$ kategori baik, 95\% kategori sangat baik, dan 98.88\% dengan kategori sangat baik.rata-rata $87.15 \%$ kategori sangat baik.

Dari hasil penelitian diatas dapat peneliti simpulkan bahwa Penerapan Model pembelajaran Listening Team pada materi Pengaruh Revolusi Prancis, Revolusi Amerika, dan Revolusi Rusia terhadap Perkembangan Pergerakan Nasional Indonesia dapat meningkatkan Disiplin Belajar sejarah siswa kelas X SMAN 2 Kerinci.

Adapun Perbandingan persentase Hasil penelitian dapat dilihat sebagai berikut:

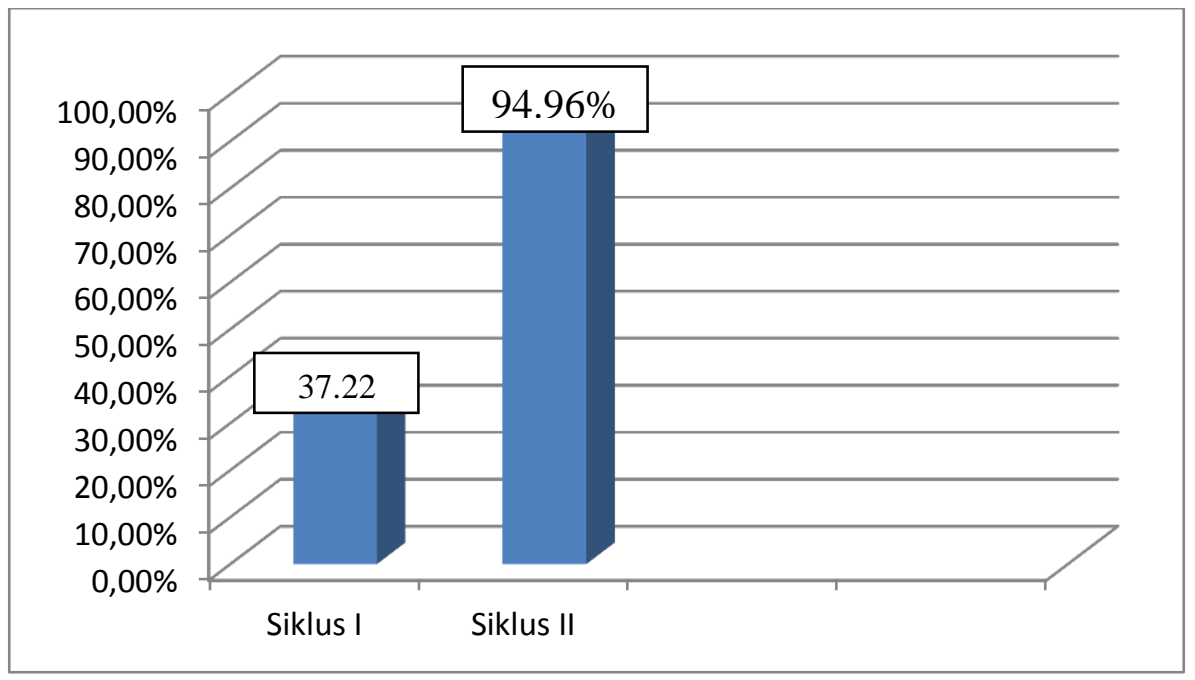

Diagram 1. Aktifitas Guru 
Historia: Jurnal Program Studi Pendidikan Sejarah

Vol 4. No 1 (2019):58-68

P-ISSN 2301-8305

E-ISSN 2599-0063

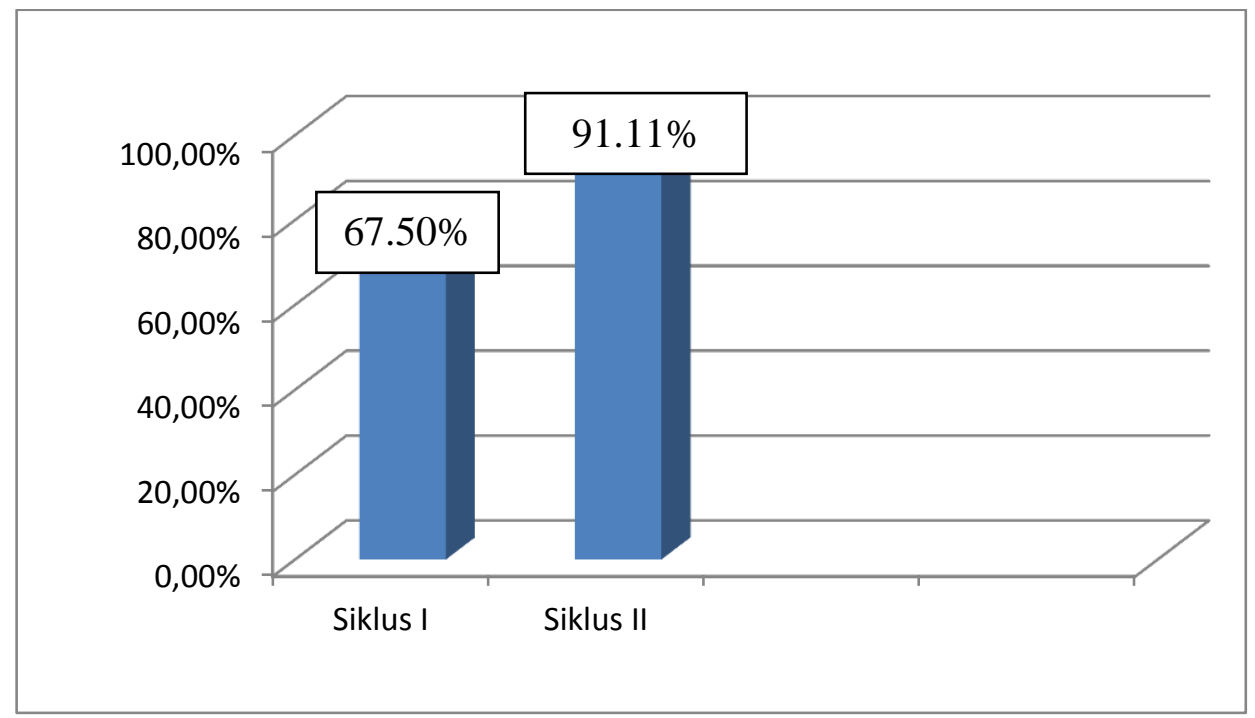

Diagram 2. Aktifitas siswa

\begin{tabular}{|c|c|c|c|c|c|}
\hline \multirow[b]{2}{*}{ No } & \multirow[b]{2}{*}{ Aspek Yang diamati } & \multicolumn{2}{|c|}{ Persentase } & \multirow[b]{2}{*}{ Selisih } & \multirow[b]{2}{*}{ Keterangan } \\
\hline & & Siklus I & $\begin{array}{l}\text { Siklus } \\
\text { II }\end{array}$ & & \\
\hline 1. & Siswa Patuh Terhadap Guru & 47.5 & 87.53 & 40.3 & Meningkat \\
\hline 2. & Siswa datang tepat waktu & 57.5 & 87.5 & 30 & Meningkat \\
\hline 3. & $\begin{array}{l}\text { Siswa disiplin mengerjakan } \\
\text { Tugas }\end{array}$ & 49.16 & 85 & 35.84 & Meningkat \\
\hline 4. & Siswa Fokus Belajar & 45 & 87.5 & 42.2 & Meningkat \\
\hline 5. & $\begin{array}{l}\text { Siswa mendengarkan } \\
\text { Penjelasan Guru }\end{array}$ & 52.5 & 89.16 & 36.66 & Meningkat \\
\hline 6. & Siswa Tidak Ribut Di kelas & 42.5 & 89.16 & 46.66 & Meningkat \\
\hline 7. & $\begin{array}{l}\text { Siswa tidak mengganggu } \\
\text { Teman saat belajar }\end{array}$ & 45.83 & 86.66 & 40.83 & Meningkat \\
\hline 8. & $\begin{array}{l}\text { Siswa Tetap dikelas saat jam } \\
\text { belajar }\end{array}$ & 45.83 & 86.66 & 40.83 & Meningkat \\
\hline 9. & $\begin{array}{l}\text { Siswa Keluar kelas hanya } \\
\text { saat jam istirahat dan jam } \\
\text { pulang }\end{array}$ & 45 & 85 & 40 & Meningkat \\
\hline
\end{tabular}

Tabel 1. Hasil Checklist Observasi Disiplin belajar siswa Siklus I Dan II 


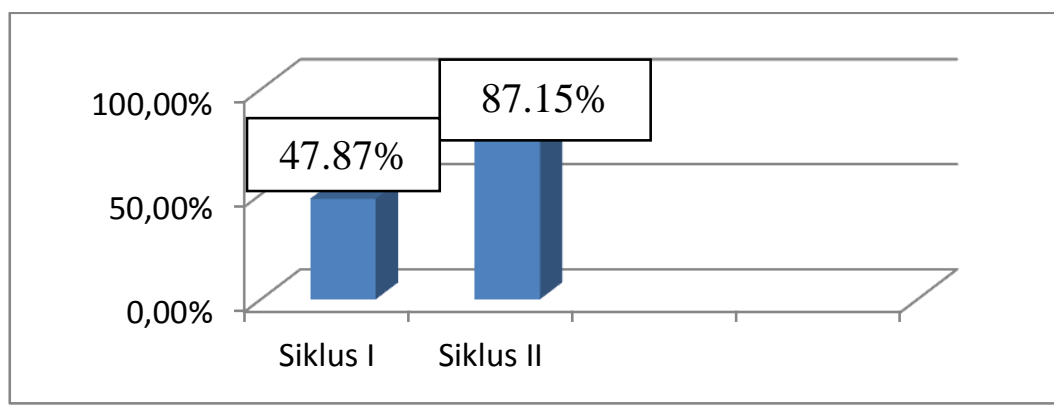

Diagram 3. Persentase perubahan Sikap disiplin belajar siswa

Dari gambar di atas dapat peneliti simpulkan bahwa terjadi peningkatan pada sikap disiplin belajar sejarah siswa. Sehingga dapat kita ketahui bahwa penerapan model Listening Teamdalam belajar sejarah sangat penting dan berguna tujuan nya untuk memperbaiki kualitas dalam pembelajaran sejarah yang mampu meningkatkan disiplin siswa sehingga mampu mencapai salah satu Indikator keberhasilan dalam dunia pendidikan yaitu Disiplin Belajar.

Berdasarkan hasil wawancara dengan guru kelas setelah dilakukan tindakan siklus I dan siklus II diperoleh informasi bahwa respon guru terhadap penggunakan dan penerapan Model Pembelajaran Listening Teampada pembelajaran Sejarah sangat baik. Karena menurut responden, Model tersebut belum digunakan di sekolah sehingga dapat memotivasi siswa terutama dalam sikap disiplin belajar mereka di kelas. Pada siklus I siswa masih bingung dikarenakan belum terbiasanya dalam menaatati peraturan secara rinci. Setelah dibiasakan dan diulang-ulang setiap harinya mereka mampu melaksanakan peraturan yang sudah ditentukan dengan sangat baik. Pada siklus II siswa sudah memamhi dan menaati peraturan. Dengan adanya Model tersebut siswa termotivasi dan bersemangat dalam melaksanakan kedisiplinan di sekolah. Selain itu, hasil disiplin belajar siswa pada siklus II meningkat menjadi $87.15 \%$ sehingga mencapai kategori yang sudah ditentukan yaitu $80 \%$. 
Historia: Jurnal Program Studi Pendidikan Sejarah

Vol 4. No 1 (2019):58-68

P-ISSN 2301-8305

E-ISSN 2599-0063

\section{KESIMPULAN}

Dari hasil pembahasan secara keseluruhan dari penelitian ini, dapat disimpulkan bahwa menggunakan Model Listening Team Dapat meningkatkan Disiplin Belajar Siswa Kelas X SMA Negeri 2 Kerinci Hal ini dapat dilihat dari indikator sikap disiplin belajar siswa. Hal ini terbukti dari peningkatan sikap disiplin belajar siswa Pada siklus I sebesar $47.87 \%$ dan siklus II Meningkat menjadi $87.15 \%$.

\section{REFERENSI}

Abdul latief.2006. Manusia Filsafat dan Sejarah. Jakarta:Bumi Aksara

Bell gredler.1994. Belajar dan Pembelajaran. Jakarta : PT Raja Grafindo Persada

Dimyati,Mudjono. 2002. Belajar dan Pembelajaran. Jakarta : Rineka Cipta

Ekosiswoyo dan Rachman.2000. Manajemen Kelas.Semarang: IKIP.

Gunning.1978. The Teaching Of History. London : Crom Helm

Ihsan 2008.Dasar-dasar Kependidikan. Bandung: Rineka Cipta Press

Kunandar.2011. Langkah Mudah Penelitian Tindakan Kelas sebagai pengembangan Profesi Guru. Jakarta:Rajawali Pres.

.2008. Langkah Mudah Penelitian Tindakan Kelas Sebagai Pengembangan Profesi Guru. Jakarta : Raja Grafindo Persada.

Lembaga Ketahanan Nasional Lemhannas,1997.Disiplin Nasional.Jakarta: PT Balai Pustaka

Mulyasa.E.2006.Menjadi guru profesional: Menciptakan pembelajaran kreatif dan menyenangkan. Bandung: Remaja Rosyada

2013. Pengembangan dan Implementasi Kurikulum 2013. Bandung: PT Remaja Rosdakarya

Max darsono. 2005. Belajar dan Pembelajaran. Semarang : CV. IKIP Semarang Press. 
Historia: Jurnal Program Studi Pendidikan Sejarah

Vol 4. No 1 (2019):58-68

P-ISSN 2301-8305

E-ISSN 2599-0063

Malvins S. Silberman. 2008. Active Learning: 101 cara Belajar Siswa Aktif. Bandung: Nuansa

Purwadarminta. 2010. Kamus Besar Bahasa Indonesia. Jakarta: Balai Pustaka

Sardiman. 2012. Interaksi dan Motivasi belajar Mengajar. Jakarta: PT. Raja Grafindo Persada

Suprijono.2009. Cooperativ Learning.Teori Dan Aplikasi PAIKEM.Yogyakarta:Pustaka Pelajar

Slameto.2003. Slameto. 2003. Belajar dan Faktor-faktor yang Mempengaruhinya. Jakarta: Rineka Cipta.

Tu’u.2004. Peran Disiplin Pada Perilaku dan Prestasi Siswa . Jakarta :Grasindo

Zainal arifin.2009. Evaluasi Pembelajaran. Bandung : PT Remaja Rosdakarya 